\title{
Lagrangian Characterization of Circulation over Submarine Banks with Application to the Outer Gulf of Maine
}

\author{
HERMAN RIDDERINKHOF* AND JOHN W. LODER \\ Physical and Chemical Sciences Branch, Department of Fisheries and Oceans, Bedford Institute of Oceanography, Darmouth, \\ Nova Scotia, Canada
}

(Manuscript received 27 October 1992, in final form 2 August 1993)

\begin{abstract}
A method to obtain an overall description of the Lagrangian circulation in complex two-dimensional timeperiodic current fields is illustrated through its application to current fields from a numerical model of the Gulf of Maine. The method, originally developed to analyze nonlinear dynamical systems, involves the identification of hyperbolic fixed points in the Lagrangian residual displacement field, and the manifolds on which particles move to or from these points. In a "regular" regime, these manifolds are separation lines that form the outer boundary of eddies within which particles remain trapped. In a "chaotic" regime, the manifolds have wild oscillations indicating a strong sensitivity of particle trajectories to their initial position and a chaotic stirring of particles across the former separation lines.

In idealized current fields for the outer Gulf of Maine, a regular regime with bank-scale eddies is found for fields composed of periodic $\mathrm{M}_{2}$ tidal currents and various linear combinations of steady currents driven by tidal rectification, wind stress, and Scotian Shelf inflow. The size, strength, and presence of the eddies depend on the current field. A chaotic regime is found in the tidal and tidal-residual currents on central Georges Bank when resolution of the small-scale topography is improved, and in the Browns Bank region when periodic currents driven by storm-intensity wind stress are added. The results are consistent with the transition from a regular to a chaotic regime being dependent on the ratio of the (periodic) particle excursion length to the horizontal scale of topographic variability. The method provides a concise description of Lagrangian circulation for spatially complex flows dominated by periodic and quasi-steady components.
\end{abstract}

\section{Introduction}

The strong spatial and temporal variability of currents in the coastal ocean can result in a complex EulerLagrange transformation and associated difficulty in predicting water parcel drift. In modeling studies of the long-term transport of materials, it is common practice to decompose the current into mean (slowly varying) and periodic (tidal) components. Subsequently, the mean component is used to obtain the advective contribution to the displacement of materials while the effect of time-dependent currents is parameterized as a diffusive process (e.g., Prandle 1984; Ridderinkhof et al. 1990). If a two-dimensional (2D) model is used, an overall description of the Lagrangian circulation can be obtained from the transport streamfunction since the material's center of mass moves along its streamlines.

\footnotetext{
* Permanent affiliation: Netherlands Institute for Sea Research, Texel, the Netherlands.

Corresponding author address: Dr. John W. Loder, Physical and Chemical Sciences Branch, Department of Fisheries and Oceans, Bedford Institute of Oceanography, Dartmouth, Nova Scotia B2Y 4A2, Canada.
}

However, this approach can fail if there are large spatial variations in the periodic and/or mean current fields over the length scale of the particle excursions. For example, significant gradients in the amplitude of tidal currents over the tidal excursion, such as across the sides of submarine banks, can result in an "advective" Stokes drift of water parcels (relative to the mean Eulerian flow) that is of the same order as the mean Eulerian current (e.g., Loder $1980)$. In areas with small-scale topographic variability, theoretical (Zimmerman 1986) and numerical (Cheng and Casulli 1982; Ridderinkhof and Zimmerman 1990) studies have shown that the interaction between tidal currents and residual "eddies" arising from tide-topography interactions (Zimmerman 1981) gives net water parcel displacements that differ substantially from those due to the Eulerian residual currents alone. Moreover, this interaction not only influences the displacement of the center of mass but can also result in a dispersive spreading of materials. Thus, in areas with topographic variations that induce significant spatial structure in the tidal and residual currents, it is a priori questionable whether a reliable description of the Lagrangian circulation can be obtained from the residual (mean) transport streamlines. 
In this paper, we illustrate a method for obtaining an overall description of the Lagrangian circulation in regions with strong periodic currents and complex topography by presenting an initial characterization of the Lagrangian circulation over the submarine bank system of the outer Gulf of Maine. Situated in an energetic tidal system, this region includes banks of different sizes (Fig. 1) over which previous observational (e.g., Butman et al. 1982; Smith 1983) and numerical (e.g., Greenberg 1983) studies have revealed strong tidal and residual currents, and energetic tide-topography interactions. In particular, it has been shown that topographic rectification of the barotropic tide makes a persistent contribution to anticyclonic residual gyres over Georges and Browns Banks (e.g., Loder 1980; Tee et al. 1987), while the currents associated with wind and Scotian Shelf inflow can contribute to the replacement of bank waters (e.g., Wright et al. 1986; Page and Smith 1989). A quantitative evaluation of Lagrangian circulation is required to determine the relative importance of various flow components to recirculation and exchange, and quantify the recirculation and residence times for applications such as the assessment of possible hydrocarbon exploration impacts (Spaulding et al. 1983) and larval retention (Iles and Sinclair 1982;
Tremblay et al. 1994; Werner et al. 1993). Considering the limited set of drifter observations from this (Beardsley et al. 1991; Drinkwater et al. 1992; Flagg et al. 1982; Smith 1989) and other regions, numerical circulation models have the potential of providing valuable information and insight.

In the spirit of emphasizing the approach and understanding key processes, we consider linear combinations of selected current components: the dominant $\mathbf{M}_{2}$ tidal current; the mean circulation associated with tidal rectification, spatially uniform wind stress, and the large-scale alongshelf current; and the time-dependent current associated with an idealized periodic wind stress. We use flow fields from a finite-element circulation model (Lynch et al. 1992; Lynch and Naimie 1993 ) that uses a harmonic method to solve the threedimensional (3D) shallow-water equations and resolves the topography of the bank sides while including influences from the adjacent Gulf of Maine and Scotian Shelf regions. With the neglect of the baroclinic flow component and the idealization of time variability, the chosen flow fields are (at best) only approximations to those in nature. They are most relevant to the winterspring regime in the outer gulf, particularly on Georges Bank, which is our primary focus. Furthermore, we

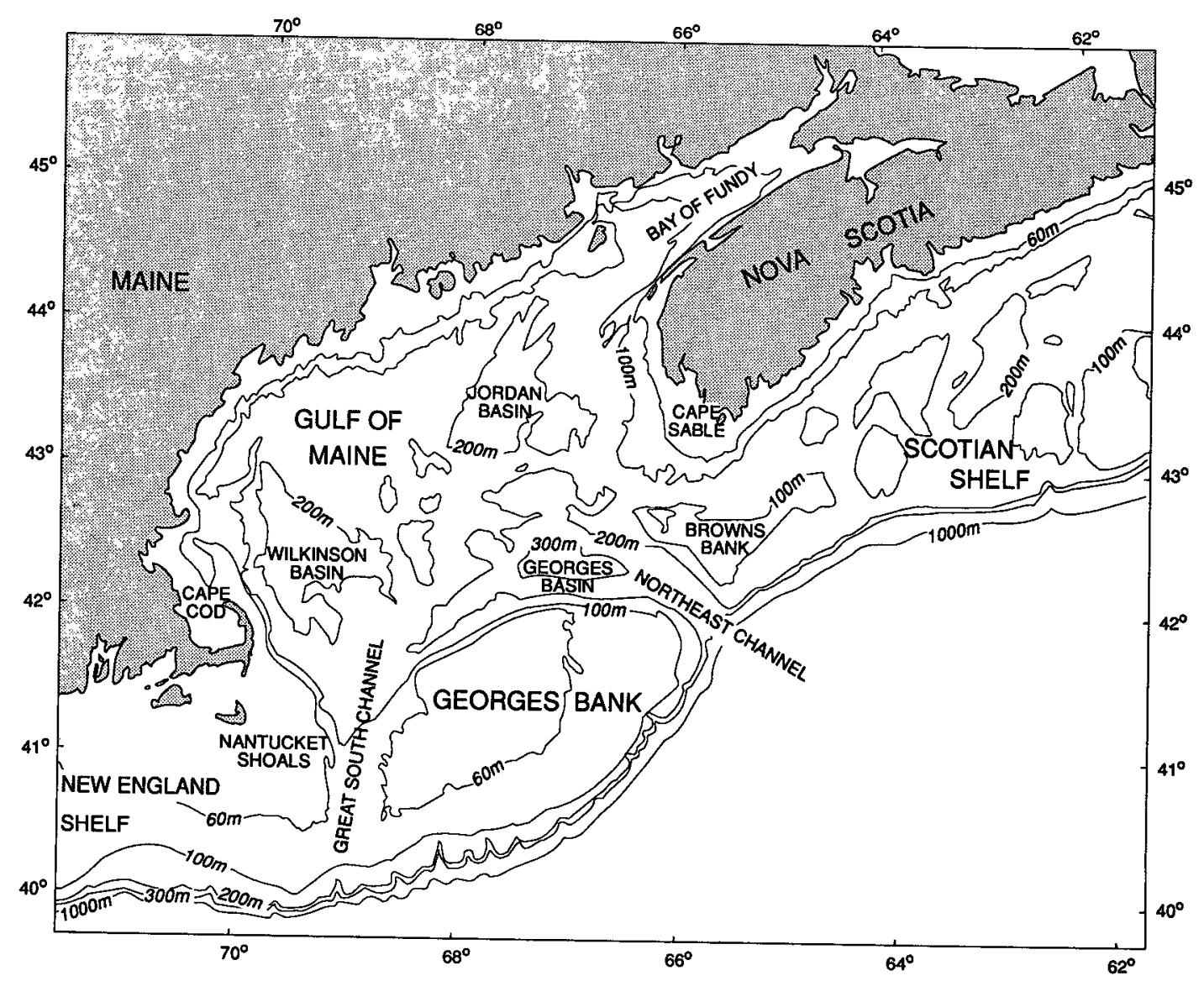

FIG. 1. Map of the Gulf of Maine region. 
make extensive use of the vertically averaged velocity fields from the 3D model solutions because of their relative simplicity and the existing framework for the Lagrangian characterization of $2 \mathrm{D}$ velocity fields. The approach involves the numerical tracking of particles to identify and describe key points in the flow fields, following the conceptual framework developed in nonlinear dynamical systems theory. Our underlying objective is to develop a context for interpreting particle trajectories in full 3D time-dependent velocity fields.

In section 2 we briefly review the theoretical basis of the approach. The circulation model and details of the analysis method are then described in section 3 . The Lagrangian characterization results for the outer Gulf of Maine banks are presented in section 4, followed by discussion in section 5 .

\section{Characterization of Lagrangian circulation in 2D time-periodic flow fields}

The recognition (Aref 1984) that the equations governing the trajectory of a particle form a (nonlinear) Hamiltonian dynamical system, in which the streamfunction plays the role of the Hamiltonian, has provided a novel framework for analyzing Lagrangian circulation in 2D time-periodic current fields. Here we introduce the approach by discussing key aspects of the theory and reviewing selected results of its previous applications. A more detailed and extended treatment can be found in textbooks (e.g., Ottino 1989; Tabor 1989).

A technique that is used to obtain insight into the overall behavior of dynamical systems is the identification of the position of, and flow around, "fixed" points-positions from which particles do not move or to which they return after one or more periods. The simplest situation is a 2D steady (mean) current field. As illustrated in Fig. 2a, the fixed points in such a current field can be either hyperbolic points (saddles) of pure strain where streamlines both converge and diverge, or elliptic points (centers) of pure rotation. Streamlines around elliptic points are closed and delineate circulation cells in which particles are trapped. If such cells exist, hyperbolic points are also present in the flow field. The streamline connected to a hyperbolic point coincides with the outermost streamline around a center and forms the boundary or separation line between the throughflow and circulation cell. Thus, the streamlines along which particles move to or from hyperbolic points can be used to delineate eddies and throughflow, which are the two basic components of a 2D steady current field.

If a time-periodic component is added to this current field, particles do not necessarily follow the streamlines of the underlying steady component. However, an appropriate analysis can be conducted using the Lagrangian residual displacement field-the displacement of particles after one period in the combined current field.
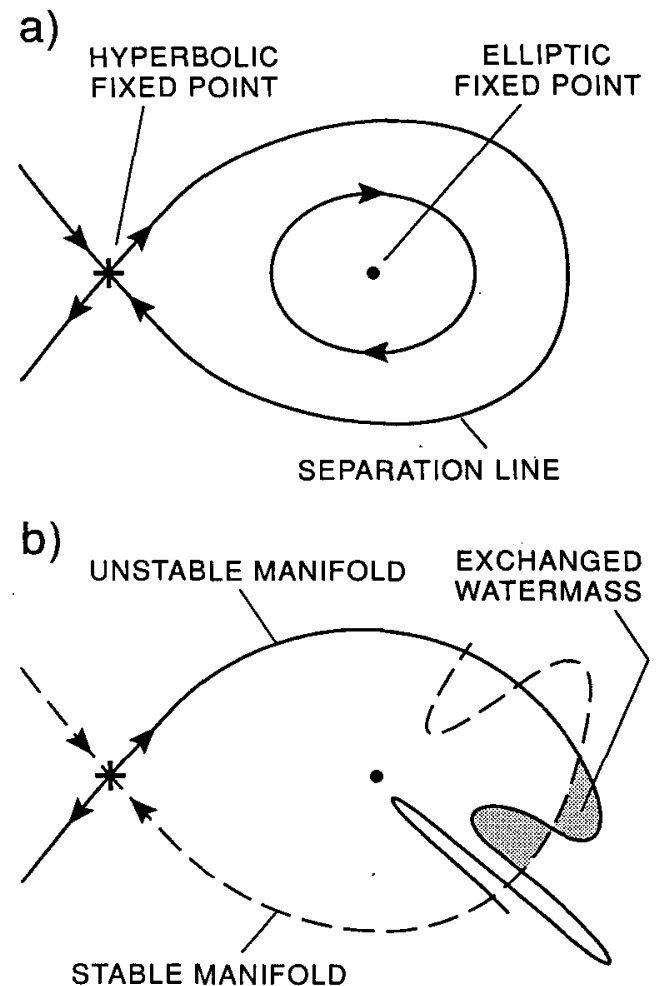

FIG. 2. (a) Streamlines and fixed points in a 2D mass-conserving steady velocity field. The separation line is formed by the outermost streamline surrounding an eddy. (b) Illustration of intersecting manifolds belonging to a hyperbolic fixed point in a $2 \mathrm{D}$ time-periodic current field with chaotic particle trajectories. The stable manifold is formed by a set of positions from which particles move toward the hyperbolic point, and the unstable manifold by a set of positions toward which particles move if they are released at the hyperbolic point.

In this case, there can again be fixed points with the basic characteristic of being either hyperbolic or elliptic. An overall description of the Lagrangian circulation can now be obtained by constructing a Poincaré section-a trajectory plot with positions shown at an interval of one tidal period-for those particles that move to or from the hyperbolic points. These position loci are referred to as the "stable" (incoming) and "unstable" (outgoing) manifolds of the hyperbolic points. Depending on the specific properties of both the steady and time-periodic current fields, the overall Lagrangian circulation can now either be similar to the streamline field in Fig. $2 a-a$ "regular" regime-or change to the so-called chaotic regime of Fig. $2 b$. In the latter case, the stable and unstable manifolds do not coincide and form a closed cell, but intersect an infinite number of times. Then, in contrast to the steady case, there is an exchange of particles across the former separation line and "chaotic stirring" occurs, which includes an extreme sensitivity of particle trajectories to their initial position. In general the area influenced by the chaotic 
stirring increases if the amplitude of the periodic current component increases (Ryrie 1992).

Although some studies have stressed the general importance of the location and classification of fixed points for the overall description of current fields (e.g., Perry and Chong 1987), most applications have concentrated on the mixing properties of chaotic systems (Ottino et al. 1988; Weiss and Knobloch 1989; Aref 1991; Pierrehumbert 1991). For tidal systems, chaotic advection has been proposed as an alternative mechanism to classical shear dispersion for the large dispersion rates often observed (Pasmanter 1988; Zimmerman 1986). Ridderinkhof and Zimmerman (1992) have shown that chaotic particle trajectories occur when the ratio between the tidal excursion length and the topographic eddy scale exceeds a critical value of $O(1)$. Below this value, particle trajectories are "regular" and similar to those in the residual current field alone.

The outer Gulf of Maine bank system, with its quasisteady residual gyres and Scotian Shelf inflow together with time-dependent tidal and wind-driven currents, is suited to this conceptual approach. It provides an interesting contrast to the Wadden Sea in that the tidal excursions are generally substantially less than the bank scales. On the other hand, the particle excursions associated with wind-driven flows are less well known, but may be comparable to the bank scale in at least the Browns Bank case (Loder et al. 1988; Page 1990). Central Georges Bank is a much stronger candidate for chaotic stirring because of its large tidal excursions and complex smaller-scale topography (Jordan 1962).

\section{Circulation model and analysis method}

\section{a. Model and solution method}

The circulation model is based on the horizontal momentum equation for a homogeneous fluid

$$
\frac{\partial \mathbf{v}}{\partial t}+\mathbf{f} \times \mathbf{v}+g \nabla_{h} \eta-N \frac{\partial^{2} \mathbf{v}}{\partial z^{2}}=-\mathbf{v} \cdot \nabla \mathbf{v},
$$

and the vertically averaged continuity equation

$$
\frac{\partial \eta}{\partial t}+\nabla_{h} \cdot(h \overline{\mathbf{v}})=-\nabla_{h} \cdot(\eta \overline{\mathbf{v}})
$$

where using conventional notation: $t$ is time and $(x$, $y, z)$ are Cartesian coordinates with $z$ positive upward and zero at the sea level in the absence of motion, $\mathbf{v}(x$, $y, z, t)=(u, v, w)$ is the fluid velocity vector, $\mathrm{f}$ is the Coriolis vector, $g$ is the gravitational acceleration, $\nabla_{h}$ is the horizontal gradient operator, $\eta(x, y, t)$ is the surface elevation, $N(x, y, t)$ is the vertical eddy viscosity, $h(x, y)$ is the water depth (more precisely, the depth of a level in the bottom constant stress layer at which boundary conditions are applied $)$, and $\overline{\mathbf{v}}(x, y$, $t)=(\bar{u}, \bar{v})$ is the vertical average of the horizontal velocity. The surface and bottom boundary conditions are taken as

$$
\begin{aligned}
& N \frac{\partial \mathbf{v}}{\partial z}=\mathbf{S} \quad \text { at } \quad z=0 \\
& N \frac{\partial \mathbf{v}}{\partial z}=C_{d}|\mathbf{v}| \mathbf{v}+0.00035 \mathbf{v} \quad \text { at } \quad z=-h,
\end{aligned}
$$

where $\mathbf{S}$ is the wind stress forcing, $C_{d}$ is a bottom drag coefficient taken as 0.005 , and the last term (SI units) in the quadratic stress law (4) represents the contribution of background currents (assumed of order 0.07 $\mathrm{m} \mathrm{s}^{-1}$ ) to the bottom current magnitude. The eddy viscosity is taken as vertically uniform but horizontally varying:

$$
N(x, y, t)=N_{0}|\overline{\mathbf{v}}|^{2}+0.002,
$$

with $N_{0}=0.2 \mathrm{~s}$ following Davies and Furnes (1980) and a background value of $0.002 \mathrm{~m}^{2} \mathrm{~s}^{-1}$.

The equations are solved on a triangular finite-element horizontal mesh extending from the Scotian Shelf into the Mid-Atlantic Bight (see Fig. 2b of Lynch and Naimie 1993), with resolution of order $5 \mathrm{~km}$ over the outer Gulf of Maine banks (e.g., Fig. 4a). Two versions of the bathymetry are considered: a base case in which values interpolated onto the grid from chart observations have been further smoothed using optimal linear interpolation (Bretherton et al. 1976) with a horizontal correlation scale of $15 \mathrm{~km}$ (Fig. 3), and the unsmoothed interpolated bathymetry that partially resolves the small-scale variability. The vertical grid uses sigma $(z /$ $h$ ) coordinates with 21 nodes and increased resolution in the surface and bottom Ekman layers.

The basic solution method is the linear harmonic method of Lynch et al. (1992) in which the horizontal and vertical structures are decoupled, extended by Lynch and Naimie (1993) to include advective and frictional nonlinearities for the tidal and tidal-residual currents. The vertical average of the momentum equation ( 1 ) is combined with the continuity equation ( 2 ) yielding a Helmholtz equation for $\eta$ at a particular frequency, which is solved using a horizontal Galerkin method on linear triangles. Upon numerical computation of the horizontal velocity's vertical structure, the vertical velocity is obtained from a Galerkin form of the continuity equation differentiated with respect to $z$,

$$
\frac{\partial}{\partial z}(\nabla \cdot \mathbf{v})=0,
$$

subject to standard surface and bottom kinematic boundary conditions.

The solution for the tidal and tidal-residual flow components is obtained through convergent iteration of coupled harmonic equations at the tidal and zero frequencies, with $\mathbf{S}=0$ and the nonlinear terms in (1), $(2),(4)$, and (5) included via a perturbation expansion 
(Lynch and Naimie 1993). For the $\mathbf{M}_{2}$ tidal frequency, elevations on the open boundaries are specified as in Lynch and Naimie (1993), and the condition of no normal flow is imposed at coastal boundaries. For the tidal residual, no normal flow is imposed at the (truncated) Bay of Fundy (BF) and coastal boundaries, and zero elevation is specified at other open boundaries. The solution is similar to the G2S solution described in Lynch and Naimie (1993).

The solutions for wind forcing and Scotian Shelf inflow are obtained from the linear versions of (1), (2), (4), and (5) following Lynch et al. (1992): the terms on the right-hand side of (1) and (2) are omitted, and $|\mathbf{v}|$ and $|\overline{\mathbf{v}}|$ on the right-hand side of (4) and (5) are specified from the tidal plus tidal-residual solution. The wind stress is specified in (3), no normal flow is imposed at the BF and coastal boundaries, a geostrophic condition is used on the downstream crossshelf boundary, and zero elevation is specified on other open boundaries. The Scotian Shelf inflow is specified through an appropriate setup of the coastal node on the upstream (Cabot Strait) boundary, with other boundary conditions as in the wind solutions. Composite flow fields are obtained by (linearly) adding various combinations of these solutions to the nonlinear tidal plus tidal-residual solution. While the resulting flow fields are only approximations to reality (or even the full equations of motion ) due to various assumptions in the model and applications herein, the representations of the primary dynamics and forcings (except the baroclinic pressure field) are expected to be adequate for an instructive initial characterization of bank-scale Lagrangian circulation in the outer Gulf of Maine.

\section{b. Analysis method of Lagrangian circulation}

Since a general method does not exist for the analysis of 3D (time-dependent) Lagrangian circulation, we use the 2D time-periodic method discussed in section 2 to obtain an initial description of the horizontal structure of Lagrangian circulation over the outer gulf's banks. We primarily consider vertically averaged velocity fields in which horizontal particle motion can be interpreted as that of stretchable water columns. The basic approach is to locate the positions of the key hyperbolic points and associated manifolds in different composite flow fields from the model.

In the steady case, the approximate positions of the hyperbolic points are found from visual inspection of the velocity field. Their "exact" positions are then determined from either interpolation or particle tracking in the velocity field within elements (using the same interpolation technique as in the solution method). Each unstable manifold is found by releasing a particle near the hyperbolic point and tracking it as it moves away, while each stable manifold is obtained by finding a release position from which a particle approaches the hyperbolic point. The accuracy of locating the positions of fixed points and the manifolds is a subjective choice; here the positions were determined with an accuracy of about $10 \mathrm{~m}$, while the iterative process of finding the stable manifolds was continued until no further visual improvements could be achieved. The method selects the transport streamlines that are connected to the hyperbolic points.

In the analysis of velocity fields composed of steady and periodic components, the same basic approach is followed in that the locations of hyperbolic points and their associated manifolds are determined. However, the approximate positions are now obtained using the Lagrangian residual displacement field, which is determined by seeding the area of interest with particles and calculating their position after one period. This field includes the effect of spatial variability in the Eulerian steady and periodic velocity fields (LonguetHiggins 1969) and is dependent on the initial phase of particle release (e.g., Cheng et al. 1986). The exact locations of the hyperbolic points and manifolds are found by particle tracking similar to that in the steady case. In the Poincaré sections, particle positions on the manifolds are shown at one-period intervals, while the character of the manifolds is determined by releasing many particles near each hyperbolic point (in contrast to the steady case where one particle suffices). When the Euler-Lagrange transformation does not lead to chaotic trajectories, particle positions in the Poincare section are on regular curves similar to the steady case, whereas "wild" oscillations are present if the system is chaotic. Locating the exact positions of the manifolds may then be difficult in practice: computer round-off errors can make the location of very irregular manifolds impossible.

In all cases, we use the 2D particle-tracking algorithm of Blanton (1991), which employs a standard fourthorder Runge-Kutta integration scheme with adaptive step size control.

\section{Results}

In this section we describe Lagrangian circulation over the outer Gulf of Maine banks using the above approach. Results are shown for areas with water depths less than $100 \mathrm{~m}$ and for current fields with increasing complexity and reality through the inclusion of additional flow components. With our emphasis on bankscale circulation features, we generally use flow fields computed using the smoothed bathymetry (Fig. 3 ) in order to minimize the effects of inadequate model resolution. However, as an illustration of the chaotic regime, we include a preliminary analysis of tidally driven flow on central Georges Bank computed with increased resolution of the small-scale topography.

\section{a. Tidal current fields}

\section{1) BANK-SCALE CIRCULATIONS}

The semidiurnal tidal current is the dominant flow component in the outer gulf and also makes a major 


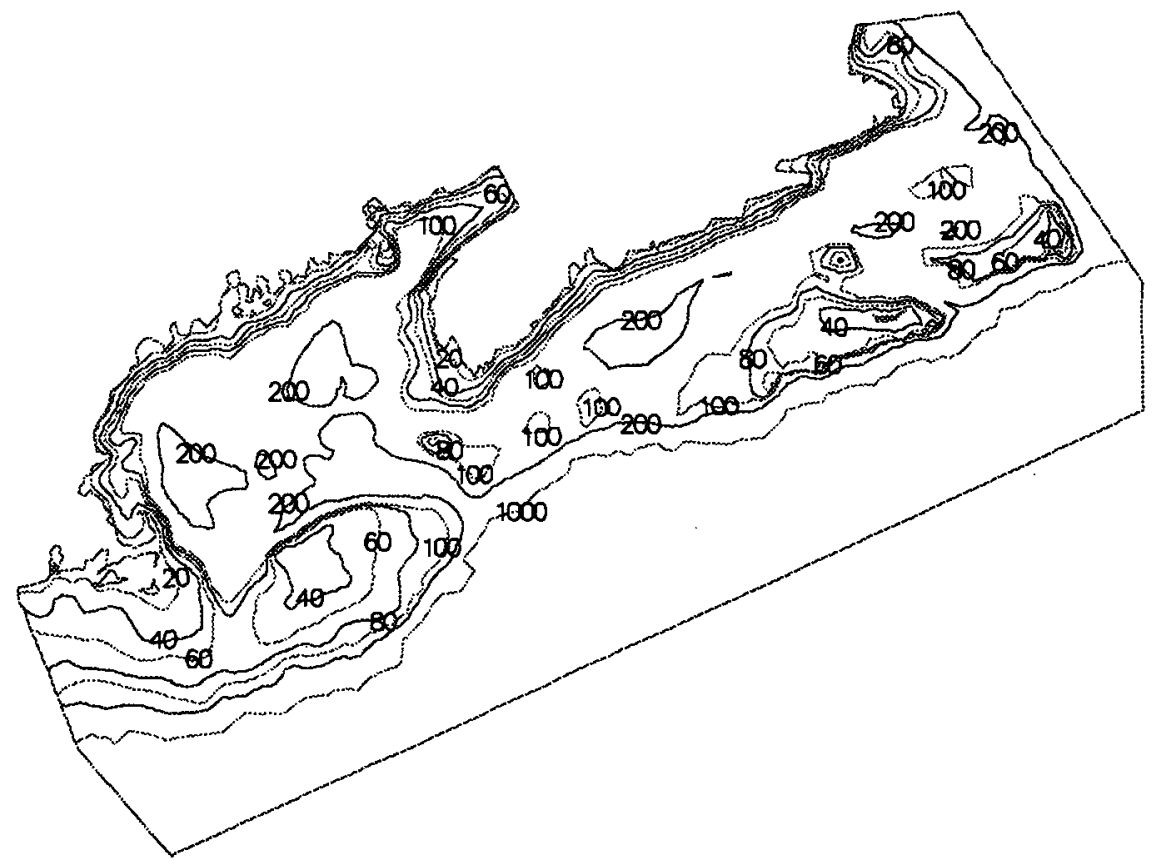

Fig. 3. Domain of the finite-element circulation model with smoothed bathymetry (in $\mathrm{m}$ ).

contribution to the residual circulation over its banks through barotropic tidal rectification (e.g., Butman and Beardsley 1987a). We start our analysis of the tidal and tidal-residual solution with the (Eulerian) residual transport velocity (Zimmerman 1979) defined by

$$
\mathbf{v}_{r t}=\frac{1}{h T} \int_{-T / 2}^{T / 2} \int_{-h}^{\eta} \mathbf{v} d z d t
$$

where $T$ is the tidal period. This steady velocity should have a nondivergent transport $\left(h \mathbf{v}_{r t}\right)$, so that particles (water columns) follow the associated streamlines.

The transport velocity field (Fig. 4a) is in general agreement with previous model results for the region (Greenberg 1983; Isaji and Spaulding 1984; Tee et al. 1987) comprising anticyclonic circulations around banks and other shallow areas and cyclonic circulations over basins and channels [see Lynch and Naimie (1993) for detailed discussion of the tidal and tidalresidual current fields]. The hyperbolic points and associated manifolds are shown in Fig. 4b, which confirms that the flow can be subdivided into closed circulation cells and areas of throughflow, as suggested by the velocity field. The location and structure of these cells reflect the bathymetry of the banks and channels, as well as the coastline. The largest cell occurs over Georges Bank (GB), with associated hyperbolic points in Great South Channel (GSC) and on the bank's northwestern corner (as well as others not shown). Smaller-scale cells and associated fixed points also occur on the top of GB. There are two closed areas on Browns Bank (BB) comprising distinct eddies around its western cap (BBW) and eastern extension (BBE). The large-scale circulation over Nantucket Shoals (NSh) is not closed, but two small-scale anticyclonic eddies can be recognized. Off southwest Nova Scotia (SWNS) there is a cyclonic closed area, probably associated with the combined influences of the bathymetry and coastline on the tide-topography interaction (Tee et al. 1993). In addition, there are cyclonic eddies (not shown) in relatively deep areas such as Georges Basin, but the currents associated with these are generally weak (Fig. 4a).

Nondivergence of the transport should cause an exact overlap of the incoming and outgoing manifolds that separate the closed areas from the remainder of the flow. However, small "gaps" between the manifolds can be seen in some cases, apparently related to small local divergences/convergences in the model current field. Such errors are a general discretization property of numerical solutions, but may also be influenced in the present case by the strong topographic variability and/or the overall computational procedure.

The excursion over a single period of particles (columns) released at slack water before ebb flow in the (vertically averaged) $M_{2}$ tidal current field alone is shown in Fig. 5a, illustrating that the excursion scales are generally smaller than the bank scales. The Poincaré section (Fig. 5b) derived from the Lagrangian residual displacement field for the tidal and tidal-residual currents provides an overall picture of the Lagrangian flow. No chaotic particle trajectories (no wild oscillations of unstable manifolds) are present. Thus, there is no ex- 

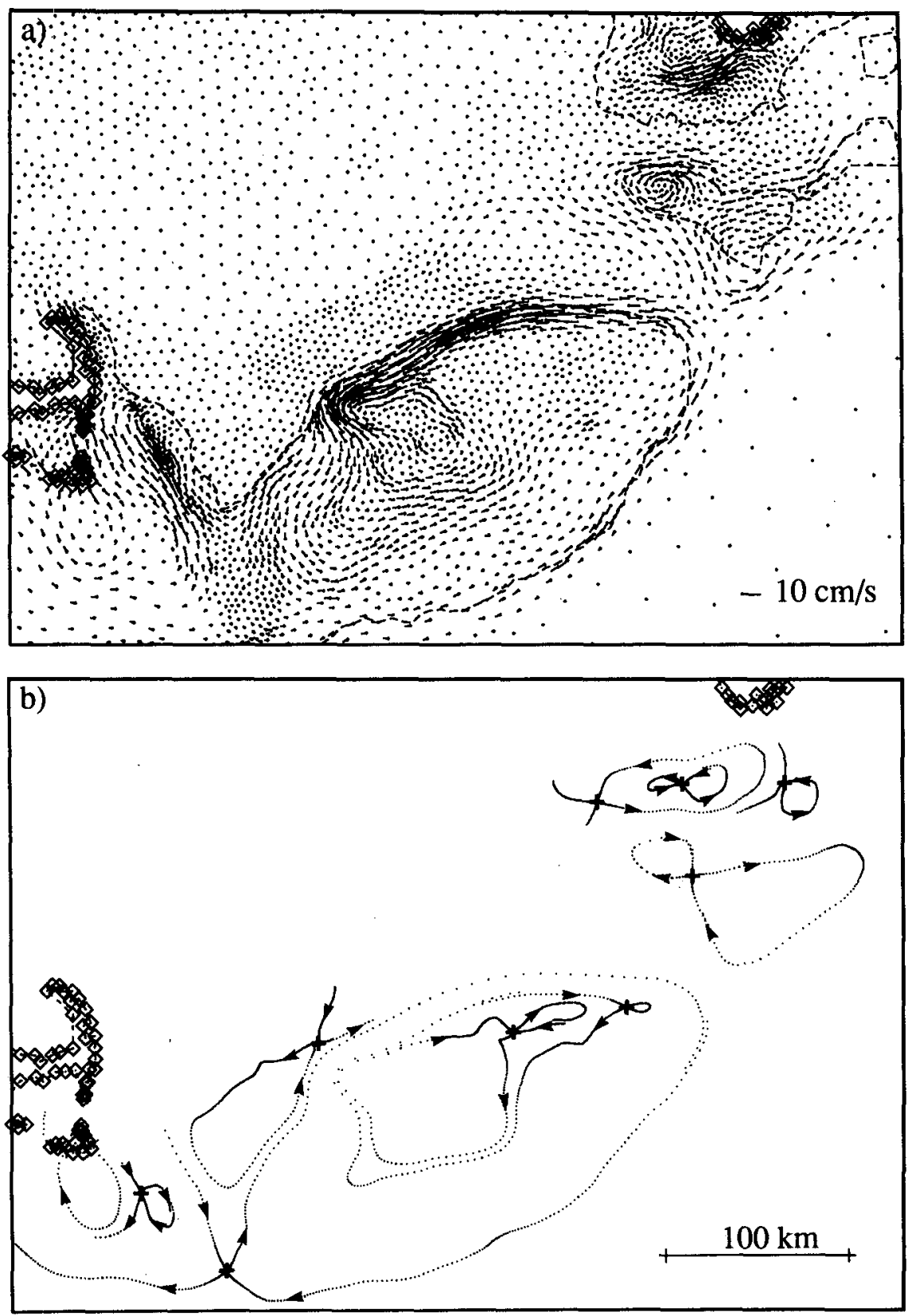

FIG. 4. (a) Tidally driven residual transport velocities in the outer Gulf of Maine (shown for each model node). The convention throughout the paper is a cross at the origin of each line vector. The dashed line is the $100-\mathrm{m}$ isobath (only included for outer gulf banks). (b) Hyperbolic fixed points $(+)$ and separation lines in the Lagrangian flow for the transport velocities in (a). The time interval between successive dots on the separation lines is two tidal periods.

change of particles across the manifolds, which can therefore be interpreted as separation lines with a similar physical meaning to the streamlines connecting saddle points in a steady flow field.

Comparison of Figs. $4 \mathrm{~b}$ and $5 \mathrm{~b}$ indicates that the addition of the $\mathrm{M}_{2}$ tidal current does not change the position of the separation lines around the banks substantially, nor the sense of rotation within the bank- scale eddies. However, the fixed points and associated small-scale eddies on NSh and GB, and within the SWNS eddy are not present in the combined current field, although there is a new fixed point on GB. This destruction of small-scale Eulerian residual eddies occurs because spatial variations in the tidal current can cause a Lagrangian residual displacement that is larger than the displacement due to the residual current. 
An important feature of the large-scale GB eddy is its asymmetric transport distribution (also see Fig. 4a), whereby because of different bathymetries the same net transport occurs over a much broader region on the southern compared to the northern flank. As a result of the weaker residual flow on the southern flank, the position of the separation line there is generally more sensitive to the addition of other flow components (see below).

The gaps between separation lines (nonoverlap of manifolds) in the Poincare section (Fig. 5b) are larger than in Fig. 4a, indicating that the magnitude of the numerical divergences/convergences is larger. For GB, the gaps have the consequence that all particles released within the separation lines eventually (after more than 1000 tidal periods) leave the area, violating mass conservation. However, the underlying numerical errors influence particle trajectories mainly on long time scales compared to the recirculation time of the eddy. Although these errors do not influence the principal results in this paper, one should be aware of them in any numerical model, especially in interpreting the results from specific particle releases.

To examine the sensitivity to tidal phase at the time of the particle release, another Poincare section for the $\mathrm{GB}$ region has been calculated using slack water before flood flow as the initial phase (Fig. 5c). The results for the different initial phases are almost identical, the primary difference being an offshore shift of the separation lines by about a tidal excursion (particles released about a tidal excursion and half-period apart experience the same velocity field). The larger tidal excursion on top of the bank results in a larger shift of the separation lines. The two cases clearly show that there are areas in the vicinity of the separation lines where the initial position (or phase) is critical to a particle's long-term destination. For example, particles released between the two different separation lines on the southern flank stay within the GB eddy when released at slack water before ebb flow, whereas they leave the eddy and move into the Mid-Atlantic Bight when released at the opposite tidal phase (also see Werner et al. 1993).

\section{2) Central Georges Bank: EFFect of INCREASED TOPOGRAPHIC RESOLUTION}

The smoothed model bathymetry used in the preceeding subsection generally provides a good representation of the bottom slopes on the sides of the banks. However, the actual bathymetry on central GB is much more rugged, with depth changes of 10-40 m occurring over distances of $\mathrm{O}(10 \mathrm{~km})$ between troughs and ridges (Jordan 1962). Such small-scale topographic variability is expected to cause strong tide-topography interactions resulting in complex tidal-residual eddies (e.g., Oey et al. 1985; Abraham et al. 1987; Ridderinkhof 1989). To resolve fully the central GB bathymetry and associated flow field, a much finer numerical grid is needed.
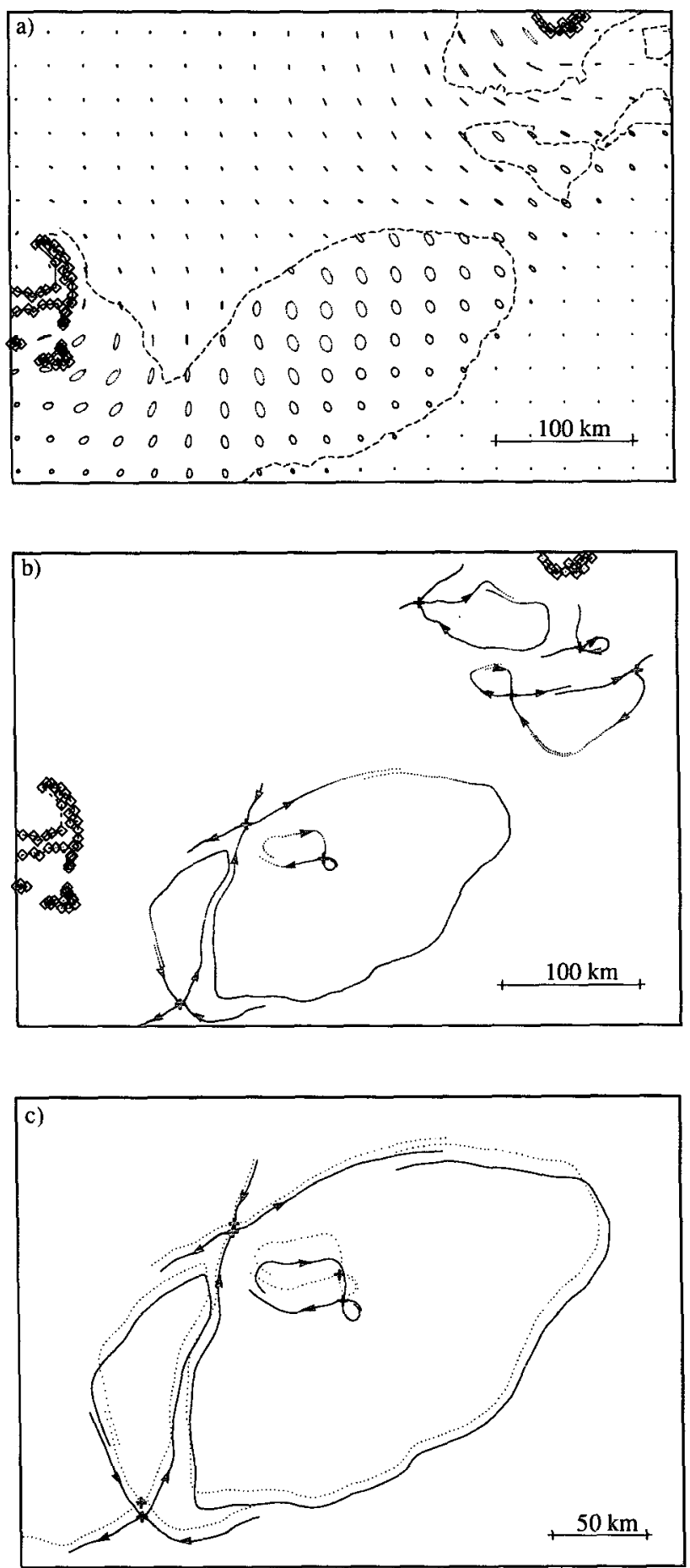

FIG. 5. (a) $M_{2}$ tidal excursions in the outer Gulf of Maine. The dashed line is the $100-\mathrm{m}$ isobath. (b) Poincare section showing the position of hyperbolic fixed points $(+)$ and associated separation lines in the outer gulf for a velocity field composed of $\mathrm{M}_{2}$ tidal and tidal-residual currents. The time interval between successive dots on the separation lines is one tidal period. (c) Poincaré section for the Georges Bank area for a velocity field composed of $\mathrm{M}_{2}$ tidal and tidal-residual currents. The section is shown for an initial release of particles at slack tide before ebb flow (dots every tidal period) and at slack tide before flood flow ( solid line). 
Here we use a tidal and tidal-residual solution obtained for the unsmoothed bathymetry on the present grid to illustrate the sensitivity of both the Eulerian and Lagrangian flows to small-scale topographic structures.

Figure 6a shows the residual transport velocity for the northwestern portion of central GB (note the bank-edge residual jet). The main difference from the base case (Fig. 4a) is a greater irregularity in the currents over the shoals, consistent with stronger tide-topography interactions. The Lagrangian residual displacement field (Fig. 6b) in this case is irregular with many more hyperbolic points. The release of 100 particles within $5 \mathrm{~m}$ of two of these points results in a Poincaré section (Fig. 6c) with wild oscillations of one unstable manifold and smaller oscillations of the other. These are fingerprints of chaotic stirring (Ridderinkhof and Zimmerman 1992) and show the extreme sensitivity of particle trajectories to initial position.

This preliminary analysis suggests that chaotic stirring is a potentially important mechanism for particle spreading and the large observed dispersion rates (Loder et al. 1982) on central GB. However, a model with a finer grid is needed to explore this in detail and quantify the associated spreading.

\section{b. Influence of other flow components}

Observations (e.g., Noble et al. 1983; Smith 1983) and modeling studies (e.g., Chapman et al. 1986; Wright et al. 1986) have shown that currents due to wind forcing and the Scotian Shelf (SS) inflow are important components of the low-frequency circulation in the outer Gulf of Maine. In some areas the magnitude of these currents is larger than the tidal residual. In this subsection, idealized representations of the 3D circulation associated with these forcings are linearly added to the tidal and tidal-residual currents discussed in section $4 \mathrm{a}$. While the resulting flow fields are increasingly realistic from a process perspective, they remain highly idealized in their representation of temporal variability. The linear superposition is an approximation that is expected to reproduce the bankscale flow structures even though local nonlinearities are not fully represented.

\section{1) SCOTIAN SHELF INFLOW}

The SS inflow is simulated through a zero-frequency linear (barotropic) solution for a $0.2-\mathrm{m}$ coastal setup specified on the upstream boundary. In combination with the tidal residual (Fig. 4a), this results in alongshelf southwestward transports of $0.45,0.51$, and $0.28 \mathrm{~Sv}$ $\left(\mathrm{Sv} \equiv 10^{6} \mathrm{~m}^{3} \mathrm{~s}^{-1}\right)$, respectively, on sections off Halifax and SWNS, and across the southern flank of GB, comparable to observed winter-spring values (Anderson and Smith 1989; Smith 1983; Flagg et al. 1982). The main features of the SS inflow are a broad region, ex-
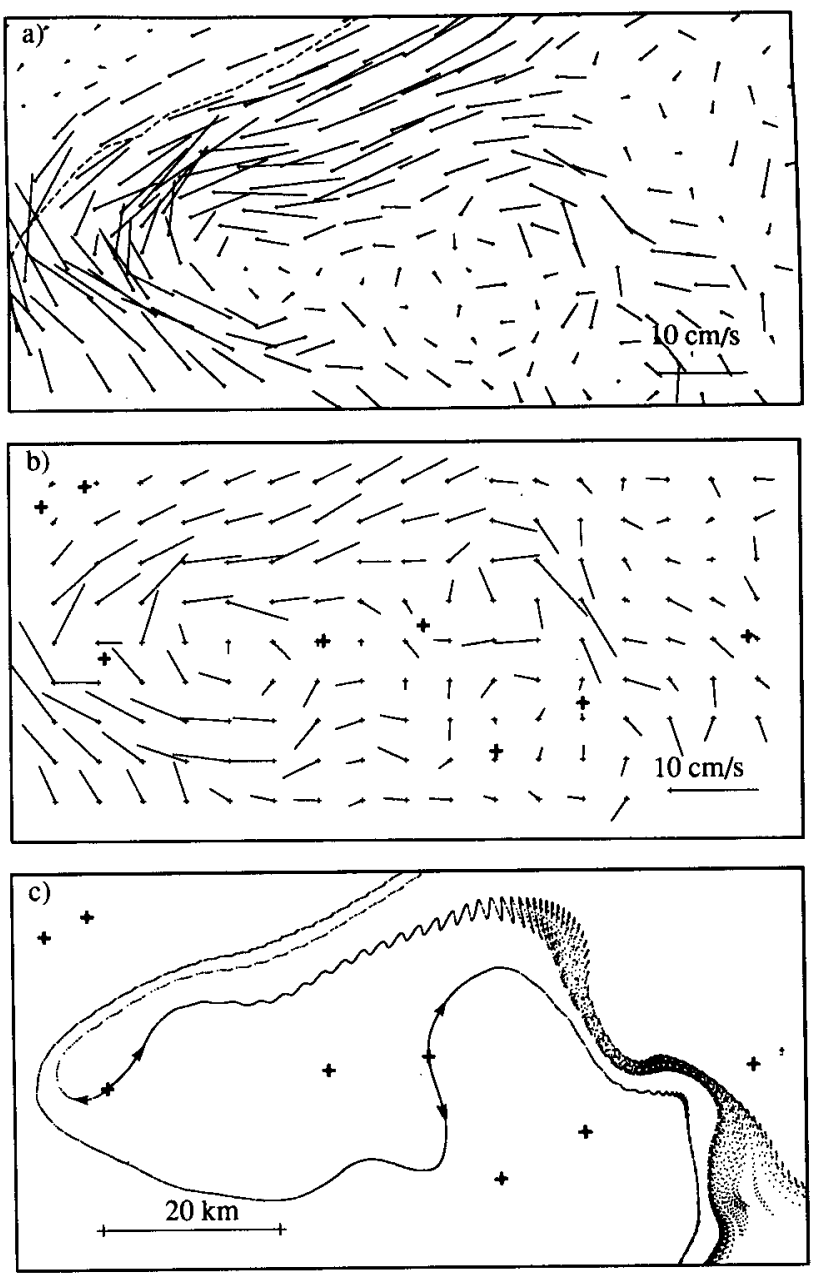

FIG. 6. (a) Tidally driven residual transport velocities on top of Georges Bank for a model run with unsmoothed bathymetry. The $100-\mathrm{m}$ isobath is shown. (b) Lagrangian residual displacement field and position of hyperbolic fixed points $(+)$ for tidal and tidal-residual velocities in the area in (a). (c) The unstable manifolds for two of the hyperbolic points in (b) shown by plotting a Poincaré section of the positions of 100 particles released within $5 \mathrm{~m}$ of these points.

tending from SWNS to BB, of relatively strong flow (about $10 \mathrm{~cm} \mathrm{~s}^{-1}$ ) into the Gulf of Maine, currents of a similar magnitude exiting Northeast Channel and flowing along the shelf break on southern GB, and weaker currents ( $2-5 \mathrm{~cm} \mathrm{~s}^{-1}$ ) along the southern flank of GB and exiting GSC toward the Mid-Atlantic Bight. On central GB and over NSh, the currents associated with this throughflow are small [see Fig. 12 of Lynch et al. (1992) for a similar flow field].

The composite (vertically averaged) residual current field (Fig. 7a) and associated Poincaré section (Fig. 7b) for the tidal flows plus SS inflow clearly show that the relatively strong and uniform currents associated with the SS inflow destroy all the Eulerian and Lagrangian circulation cells (Fig. 5b) on BB and NSh, and off SWNS. The circulation cell 

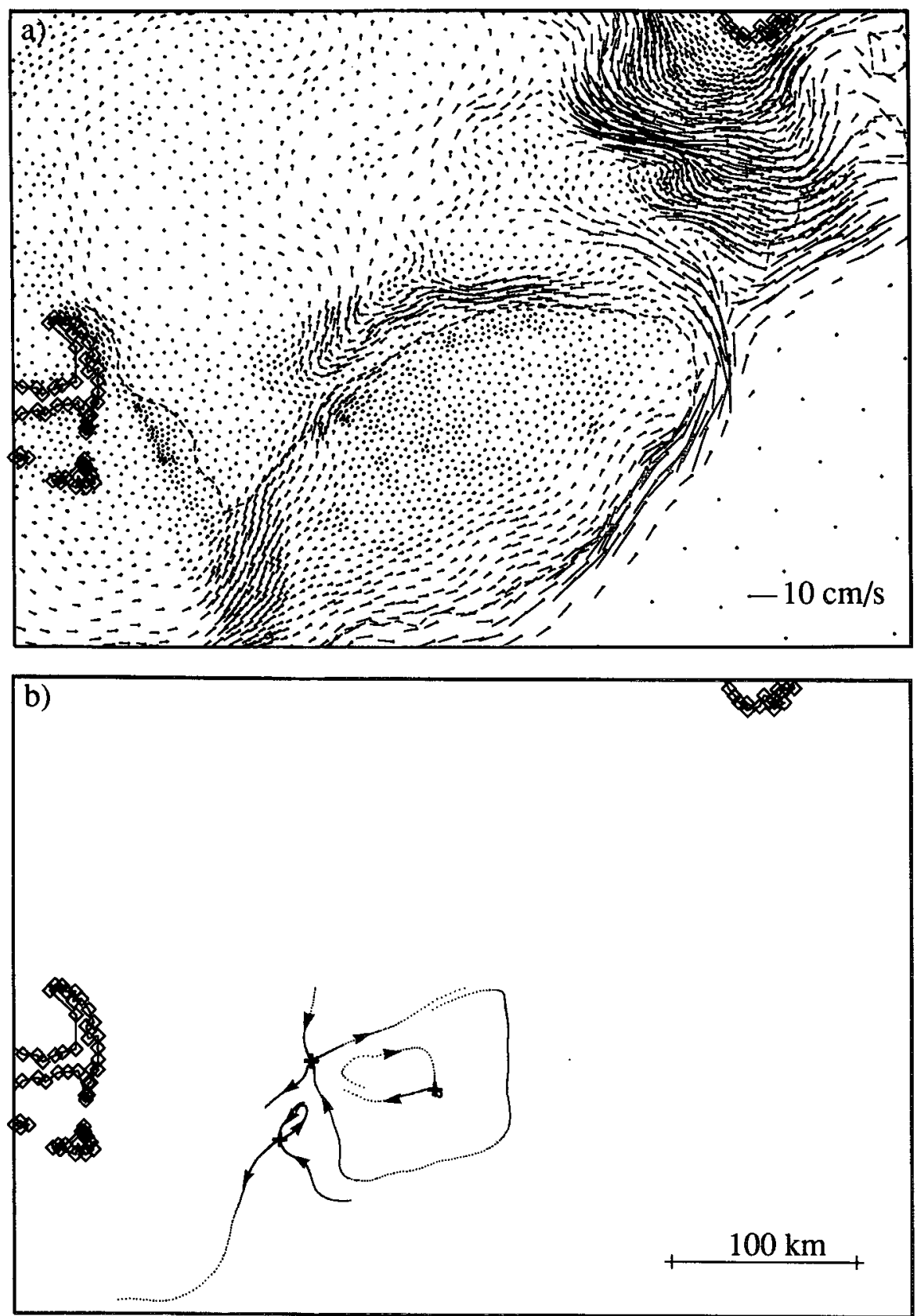

FIG. 7. (a) Vertically averaged (steady) velocity field composed of tidal residuals and Scotian Shelf inflow. The 100-m isobath is included. (b) Poincaré section showing the position of hyperbolic fixed points $(+)$ and separation lines for a current field composed of $\mathbf{M}_{2}$ tidal currents and the residual currents shown in (a). The time interval between dots on the separation lines is one period.

around GB remains present but is reduced in size, mainly due to the throughflow on the southern flank. Although the separation line on the southern flank is substantially shifted on bank, the integrated transport between the eddy center and the separation line remains about the same as in the tidal case (Fig. 5b).

\section{2) SCOTIAN SHELF INFLOW PLUS STEADY WIND FORCING}

To examine the effect of steady wind forcing on the Lagrangian circulation, we use linear model solutions for spatially uniform alongshelf and cross-shelf wind stresses of magnitude of $0.1 \mathrm{~Pa}$ (Figs. 8a,b). Because 

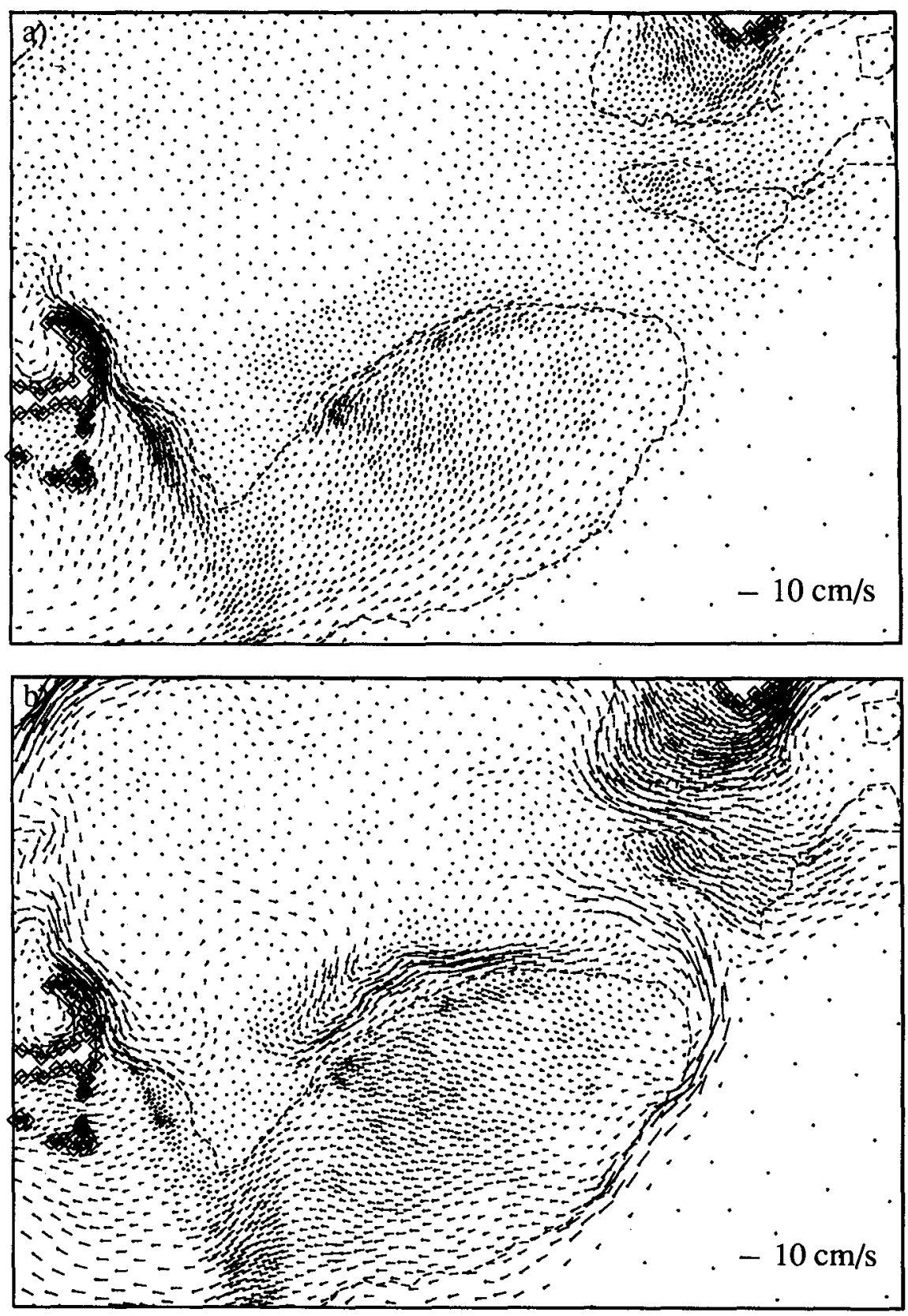

FIG. 8. Vertically averaged velocity fields due to a steady wind stress of magnitude $0.1 \mathrm{~Pa}$ (a) cross-shelf from the northwest and (b) alongshelf from the southwest, with the $100-\mathrm{m}$ isobath in background.

of the surface Ekman layer, the wind-driven flow field has more vertical structure than the tidal-residual and SS inflow components. Thus, the vertically averaged velocity fields are primarily representative of the flow outside the surface and bottom Ekman layers in deeper areas, and the interior flows in shallow areas where the water depth is less than the Ekman layer thickness. Figures $8 \mathrm{a}, \mathrm{b}$ show that both wind stress forcings result in relatively regular throughflows (compared with the tidal residuals) over the banks, with a significantly stronger response for alongshelf stress as expected (Wright et al. 1986). Note that, under the linear assumption, wind stress forcing in the opposite directions (not shown) results in current fields equal and opposite to those in Figs. 8a,b, so that the direction of the associated throughflow depends on wind direction.

Poincaré sections resulting from (vertically averaged) current fields composed of the wind-driven flow for 
each of the four orthogonal wind directions, linearly added to the tidal and tidal-residual currents and SS inflow, are shown in Figs. 9a-d for GB and NSh. Comparison of Figs. 9a,b with the case without wind-driven currents (Fig. $7 \mathrm{~b}$ ) shows that a cross-shelf wind stress results in a decreased/increased size of the closed circulation around GB when the wind is directed off/ onshore. This change in size can, similar to the effect of the SS inflow, be largely explained by the increase/ decrease in the current strength on the southern flank of GB, in contrast to the northern flank where the current strength is mainly determined by the tidal-residual contribution. The consequence is that the position of the separation line on the southern flank is much more sensitive to additional steady (relatively uniform) flow components. The small-scale eddies on central GB and NSh for a wind stress from the southeast indicate that, in this case, the wind-driven currents cancel the throughflow in certain areas. On BB and off SWNS (not shown), no eddies are present in the two crossshelf wind cases.
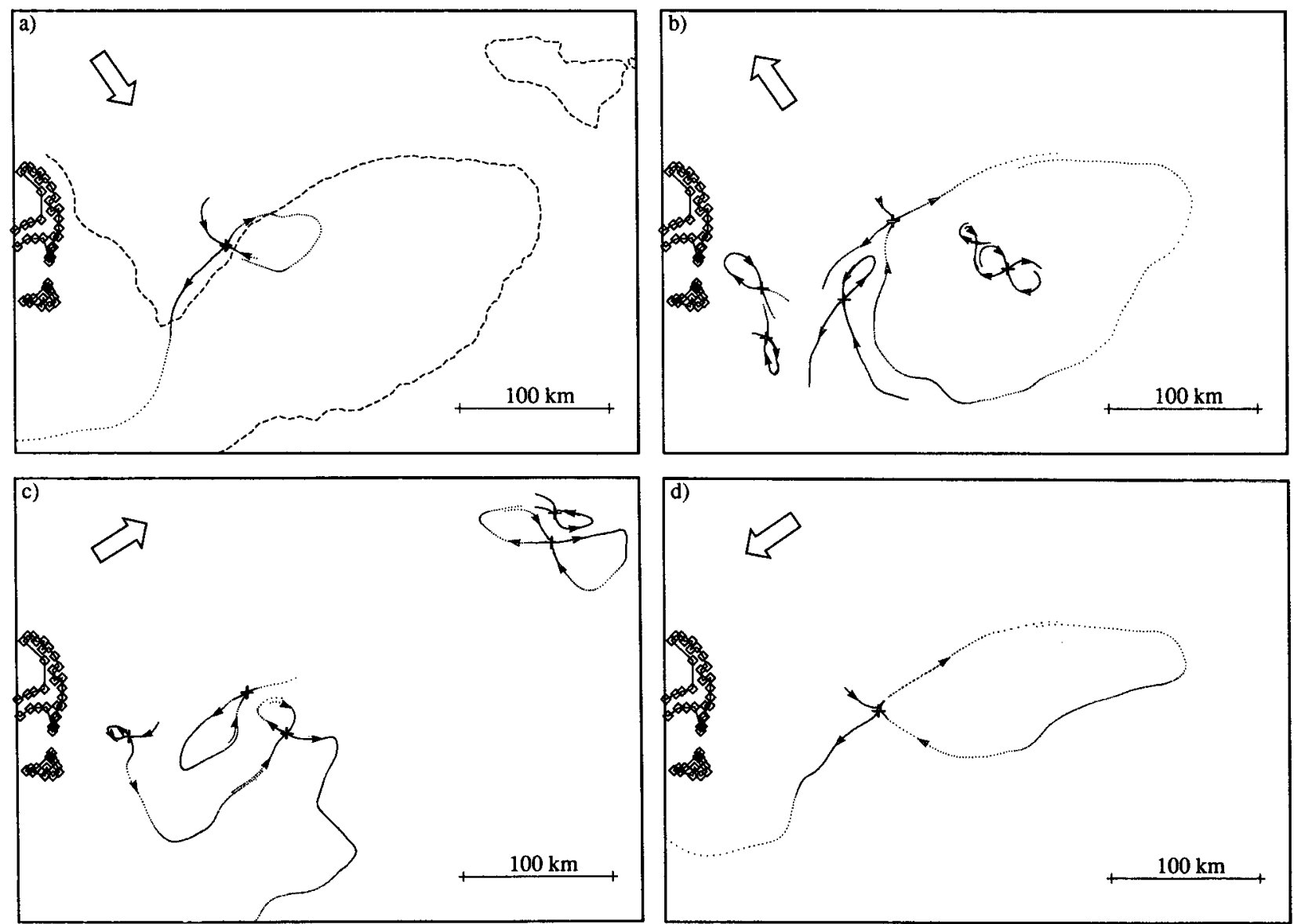

FIG. 9. Poincare sections showing the positions of hyperbolic fixed points $(+)$ and separation lines, with a time interval of one tidal period between successive dots, for velocity fields composed of $M_{2}$ tidal currents and residual currents due to (a) tides + SS inflow + cross-shelf wind stress $(0.1 \mathrm{~Pa})$ from the northwest, (b) tides + SS inflow + cross-shelf wind stress $(0.1 \mathrm{~Pa})$ from the southeast, $(\mathrm{c})$ tides + SS inflow + alongshelf wind stress $(0.1 \mathrm{~Pa})$ from the southwest, and (d) tides + SS inflow + alongshelf wind stress $(0.1 \mathrm{~Pa})$ from the northeast. The $100-\mathrm{m}$ isobath is included in (a). 
response in the presence of other flow components can be strongly asymmetric. This is particularly true in the case of a spatially asymmetric background eddy as on GB.

Analysis of the surface velocity field in the four composite solutions with wind forcing indicates a large reduction in the size of the closed area in all cases, consistent with the expected influence of a large (Ekman layer) throughflow.

\section{3) SS INFLOW PLUS PERIODIC WIND FORCING}

For an initial examination of the effects of timedependent (storm band) wind forcing, we use linear model solutions for spatially uniform along- and crossshelf wind stresses of amplitude $0.72 \mathrm{~Pa}$ (corresponding to a wind speed of $20 \mathrm{~m} \mathrm{~s}^{-1}$ ) and period $100 \mathrm{~h}$. The simplicity of both the linear model and the applied forcing means that the results can only be interpreted as indications of the possible effects of a storm. The standard deviation corresponding to the chosen wind stress amplitude is $2-3$ times the average wintertime values observed in the GB region (Saunders 1977; Butman and Beardsley 1987b), so that the results are more relevant to isolated storms than average conditions. The period of the forcing has been chosen to be an integer (8) number of tidal periods. Thus, the total current field composed of the tidal-residual and SS inflow, and the periodic currents due to the tide and the wind stress, is periodic with an interval of $100 \mathrm{~h}$.

The excursion of particles in the spatially varying velocity fields associated with the cross- and alongshelf periodic wind stress is shown in Figs. 10a and 10b. In general, the excursions are somewhat larger and more irregular for the alongshelf than for the cross-shelf stress, especially in the shallow areas off SWNS and on BB, and in Northeast Channel where the responses include large pressure-driven transports into and out of the gulf (Wright et al. 1986). Comparison with Fig. 5a indicates that in both cases the excursions are larger and more irregular than the tidal excursions.

The positions of hyperbolic points and their associated manifolds in the composite (vertically averaged) flow fields are found using the Lagrangian residual displacement field for the basic period of $100 \mathrm{~h}$. Results are shown in Figs. 11a and $11 \mathrm{~b}$ for the cross- and alongshelf wind forcing, respectively. On the northern side of GB the spreading of particles is (slightly) chaotic in both cases causing oscillations in the unstable manifold. The formal consequence is that this manifold cannot be interpreted as a separation line since an exchange of particles across it is possible. However, the volume involved in this exchange is very small for both current fields. Note that the "amplitude" of the oscillations is larger for the alongshelf stress indicating that the area influenced by chaotic stirring is larger in this case. Comparison with Fig. $7 \mathrm{~b}$ indicates that, apart from the presence of small chaotic regions, the differ-
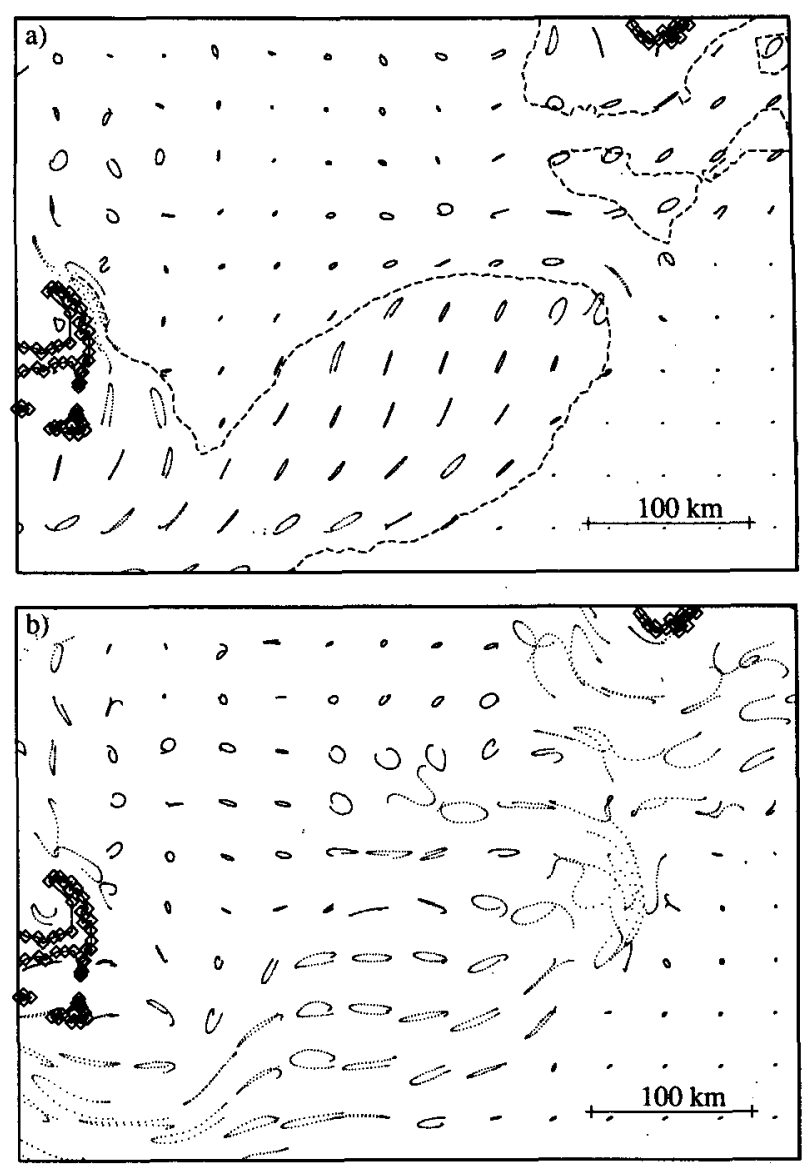

FIG. 10. Particle excursions in the vertically averaged velocity fields due to periodic wind stress in the (a) cross-shelf and (b) alongshelf directions. The stress amplitude is $0.72 \mathrm{~Pa}$ and the period is $100 \mathrm{~h}$. The 100-m isobath is included in (a).

ences between Lagrangian circulation with and without periodic wind forcing (averaged over the wind period) are only small for the GB region.

On BB there are large differences in the spreading of particles in the two composite fields considered. In the case of periodic alongshelf stress, three hyperbolic points can be identified on the bank, whereas a periodic cross-shelf stress results in a regular throughflow over the bank without any fixed points. The release of 500 . particles within $5 \mathrm{~m}$ of two of the hyperbolic points on BB in the alongshelf stress case results in the Poincare section shown in Fig. $11 \mathrm{~b}$. There is a strongly chaotic regime over $\mathrm{BB}$ in this case with very irregular manifolds, which is in contrast with the Poincare sections of all previous current fields considered. The stable manifolds are not shown, since their irregular position makes their location very difficult. However, as suggested by those parts of the manifolds in Fig. $11 \mathrm{~b}$ that leave one fixed point and pass close to another, numerous intersections between stable and unstable manifolds are present. 
To illustrate the dramatic difference between particle displacement on the tops of $\mathrm{GB}$ and $\mathrm{BB}$ (under the present idealizations), the spreading of two groups of 1000 particles initially positioned $10 \mathrm{~m}$ apart on $10-$ $\mathrm{km}$ straight lines has been calculated for a few periods. The position of these particles at the time of release and after 1 and 2 periods ( 100 and $200 \mathrm{~h}$ ) is shown in Fig. 12. It is clear that, due to stretching and folding in the chaotic regime on top of $\mathrm{BB}$, the spreading of these particles is much larger than the spreading in the regular regime on central GB (with smoothed smallscale bathymetry). The rate of growth in the length of the line of particles is exponential on BB in contrast to a linear growth rate on GB, with lengths of 2200 and $16 \mathrm{~km}$ on $\mathrm{BB}$ and $\mathrm{GB}$, respectively, after $300 \mathrm{~h}$.

\section{c. Diagnostics of the Georges Bank eddy}

An eddy on GB is a persistent feature of all the current fields that have been analyzed. However, from the position of the separation lines, it is clear that the size and location of the eddy differ substantially for the different current fields. To quantify these differences, we have determined the area within the separation lines, a characteristic circulation time, and the average velocity of particles traveling within the eddy. Both the circulation time and average velocity have been calculated by releasing particles on a straight line connecting the central elliptic point of the eddy with a separation line and, when the particles cross the line after a complete circulation, calculating the average time and distance traveled since release. Results are shown in Table 1 for the current fields due to the $\mathbf{M}_{2}$ tide alone and for the most "realistic" fields (based on wind direction) with steady components added.

Comparison of the results for the tidal fields with the other current fields indicates that the size of the eddy decreases substantially when (quasi-realistic) steady nontidal current fields are added. The consequence is that the average distance traveled by particles recirculating within the eddy is reduced, which in turn reduces the average circulation time. Another less important factor in the reduced circulation time is the increased average Lagrangian velocity within the eddy (except for the alongshelf wind stress case in which the size of the eddy is very small).

Comparison of the results for the two tidal fields indicates that including the periodic $\mathrm{M}_{2}$ currents increases the circulation time by about $30 \%$, whereas it does not influence the size of the eddy significantly. The decrease in the average Lagrangian velocity of the particles is due to the increased amplitude of the tidal currents on top of the bank (Fig. 5a) resulting in a cyclonic (Stokes) drift around the bank due to the $\mathrm{M}_{2}$ currents alone (Loder 1980).

\section{Summary and discussion}

Techniques devised for analyzing (nonlinear) dynamical systems can be a powerful tool for analyzing
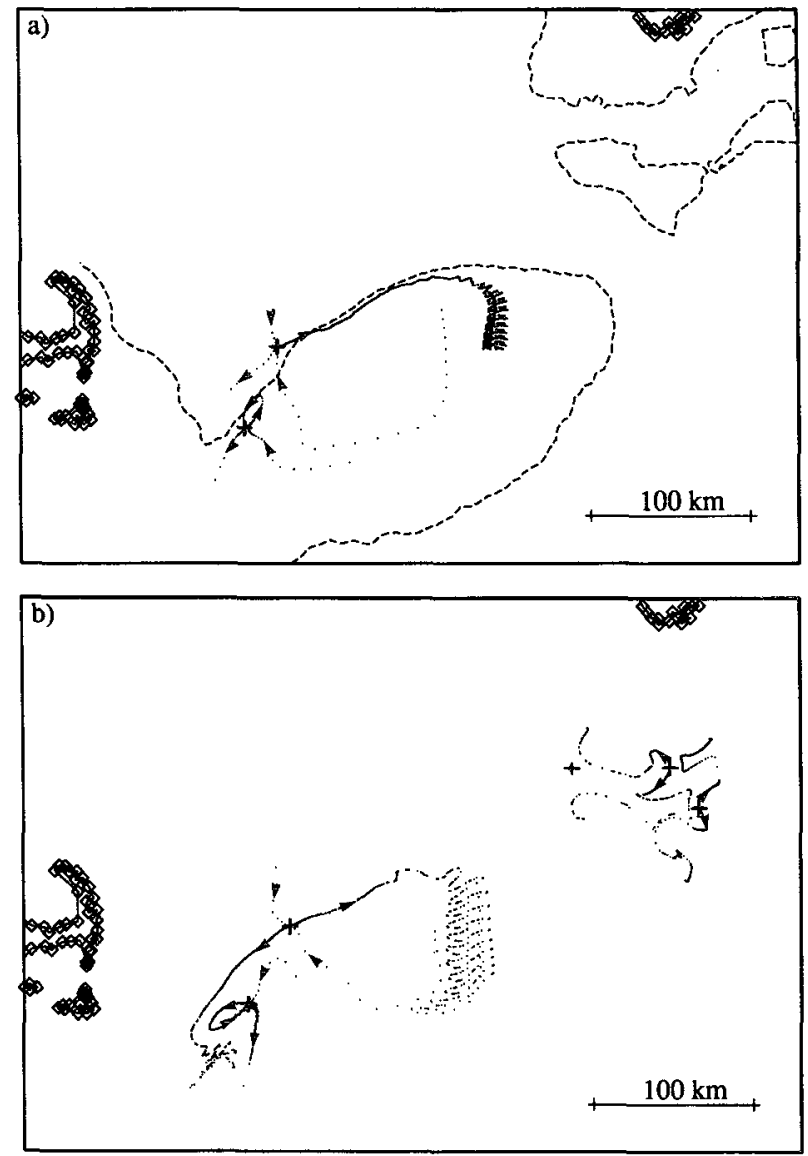

FIG. 11. Poincaré sections showing hyperbolic fixed points (+) and associated manifolds for velocity fields composed of $\mathrm{M}_{2}$ tidal currents, residual currents due to tides and SS inflow, and currents driven by periodic wind stress (Fig. 10) in the (a) cross-shelf and (b) alongshelf directions. The wild oscillating (unstable) manifolds are shown by plotting the positions of 100 particles, released close to the hyperbolic points. The regular manifolds are shown by plotting the position of one particle on these manifolds with an interval of 100 h. In (b), only three of the hyperbolic points on BB, and the unstable manifolds for two of the points, are shown.

Lagrangian flows in complex 2D time-periodic current fields. The application of these techniques to (vertically averaged) finite-element model solutions for banks in the outer Gulf of Maine has provided an initial characterization of the Lagrangian circulation associated with idealized representations of selected key processes. For the bank-scale circulation (on smoothed smallscale topography), regular (nonchaotic) particle trajectories are found for flow fields composed of steady tidal residuals and periodic $\mathrm{M}_{2}$ currents. Closed circulation cells around GB, BB, and off SWNS are present. The cells around BB and off SWNS are weak in that they disappear when a steady current field typical of the large-scale southwestward throughflow is added; in contrast, the eddy around GB decreases in size but does not disappear. With the further addition of steady current fields driven by wind stresses from the north- 


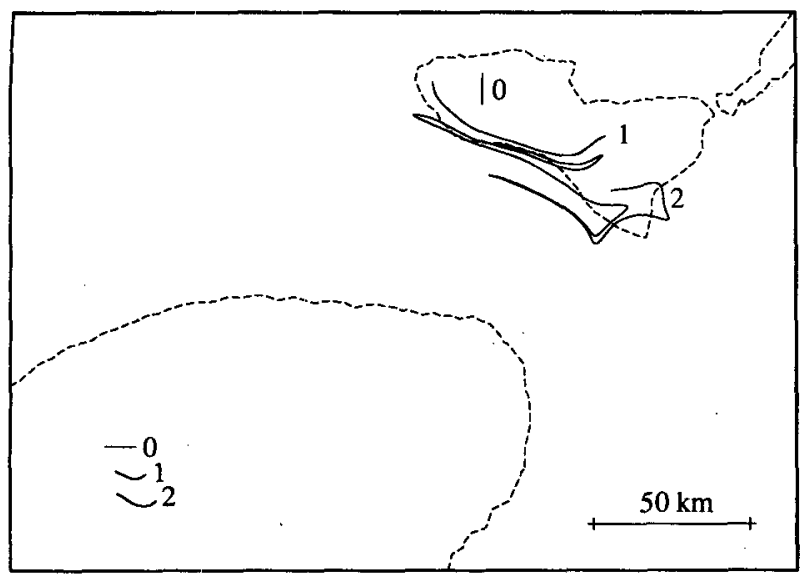

FIG. 12. Positions at the time of release $(0)$, and after $1(100 \mathrm{~h})$ and 2 periods $(200 \mathrm{~h})$, of two 10-km lines of particles initially released on the tops of GB and BB in the flow field of Fig. $11 \mathrm{~b}$.

west (typical of the winter mean) and the southwest (typical summer direction but larger magnitude), the size of the GB eddy is further reduced, while the BB and SWNS are restored in the southwesterly case through cancellation of the throughflow. On the other hand, the size of the GB eddy is increased in the less realistic cases of steady wind forcing from the northeast and southeast. While the bank-scale circulation in all cases with periodic tidal currents plus steady additional flows remains in the regular regime, there is a clear demonstration of directional asymmetry in the Lagrangian response of GB to wind stress as a result of spatial asymmetry in the tidal-residual eddy.

Indications of a chaotic regime have been found both in the bank-scale circulations and on smaller scales on central GB. With the current field driven by periodic wind stress of period and magnitude approximating an isolated storm superimposed on the tidal and tidalresidual currents and the SS inflow, there are chaotic trajectories in the bank-scale circulation on both GB and BB. On GB the chaotic trajectories occur in a small area on its northern side for both cross-shelf and alongshelf wind. On BB there are strong chaotic motions under alongshelf periodic wind stress, resulting in the rapid separation of particles. In addition, when the small-scale topography on GB is partially resolved, chaotic motion is found in the tidal and tidal-residual flows. The occurrence of chaotic trajectories both when the excursion length of particles is increased (periodic wind) and when small-scale structures in the bathymetry are included supports the importance of the ratio between the (periodic) excursion length and the length scale of spatial variations in the current field to the onset of chaotic stirring (Ridderinkhof and Zimmerman 1992).

In reality, the current fields in the outer Gulf of Maine, and in many areas of the coastal ocean with complex topography, have much greater spatial and temporal structure than those considered here, due, for example, to vertical structure, small-scale bathymetry, other tidal constituents, more complex wind forcing, baroclinicity, and additional nonlinear interactions among the flow components. In general, such additional factors increase the irregularities in the Eulerian current field, which in turn can be expected to increase the tendency toward the chaotic regime for particle trajectories. The increased complexity of the Lagrangian circulation in more realistic flow fields emphasizes the need for a systematic approach in characterizing its overall properties. The present application of nonlinear systems techniques is such an approach that can be used for the analysis of flow fields that are substantially two-dimensional and dominated by periodic and quasi-steady components. Additional analysis procedures from nonlinear systems theory (not described here) can be used to quantify further the kinematic flow properties in the vicinity of key features such as fixed points. These techniques hold potential for both identifying key features and/or processes in the more complex flow regimes generally found in the coastal ocean, and obtaining a quantitative Lagrangian description of flow regimes dominated by periodic and quasi-steady components.

Acknowledgments. We are grateful to our colleagues on the Georges Bank finite-element modeling team for their valuable contributions to this work: Dan Lynch and Chris Naimie at Dartmouth College for providing the models and for assistance in the computation of flow fields; Francisco Werner and Brian Blanton at Skidaway Institute of Oceanography for providing the particle-tracking algorithm; Dave Greenberg, Mary Jo Graça, and Poppy Shen at Bedford Institute for assistance with the model implementation; and our biological collaborators for providing additional motivation. We also thank Dave Greenberg, Dan Lynch, Peter Smith and two anonymous reviewers for constructive comments on the manuscript. This is Contribution 11 of the U.S. GLOBEC program, funded jointly by NOAA and NSF, with support also provided by the

TABLE 1. Quantitative diagnostics of the eddy on GB based on the vertically averaged velocity fields for the most realistic flow combinations considered. See text for the forcing magnitudes and evaluation methods.

\begin{tabular}{lccc}
\hline \hline $\begin{array}{c}\text { Current field } \\
\text { composition }\end{array}$ & $\begin{array}{c}\text { Surface area } \\
\left(10^{3} \mathrm{~km}^{2}\right)\end{array}$ & $\begin{array}{c}\text { Circulation } \\
\text { time (days) }\end{array}$ & $\begin{array}{c}\text { Velocity } \\
\left(\mathrm{cm} \mathrm{s}^{-1}\right)\end{array}$ \\
\hline $\begin{array}{l}\text { Tidal residual (TR) } \\
\text { Periodic } \mathrm{M}_{2} \text { tide }\left(\mathrm{M}_{2}\right) \\
+\mathrm{TR}\end{array}$ & 29.1 & 185 & 2.7 \\
$\begin{array}{l}\mathrm{SS} \text { inflow (SS) + TR } \\
+\mathrm{M}_{2}\end{array}$ & 29.3 & 251 & 2.2 \\
$\begin{array}{c}\text { Steady wind from SW } \\
+\mathrm{SS}+\mathrm{TR}+\mathrm{M}_{2}\end{array}$ & 11.5 & 48 & 2.7 \\
$\begin{array}{l}\text { Steady wind from NW } \\
+\mathrm{SS}+\mathrm{TR}+\mathrm{M}_{2}\end{array}$ & 1.8 & 17 & 1.9 \\
\hline
\end{tabular}


(Canadian) Interdepartmental Panel for Energy, Research and Development.

\section{REFERENCES}

Abraham, G., H. Gerritsen, and G. J. H. Lindijer, 1987: Subgrid tidally-induced residual circulations. Contin. Shelf Res., 7, 285305.

Anderson, C., and P. C. Smith, 1989: Oceanographic observations on the Scotian Shelf during CASP. Atmos.-Ocean, 27, 130-156.

Aref, H., 1984: Stirring by chaotic advection. J. Fluid Mech., 143, $1-21$.

- 1991: Chaotic advection of fluid particles. Philos. Trans. Roy. Soc. London A, 333, 273-288.

Beardsley, R. C., R. Limeburner, and C. Chen, 1991: Summertime Lagrangian circulation in the Great South Channel/Georges Bank region. Eos, 72, 260.

Blanton, B., 1991: Drogues.F and Drogdt.F: User's manual for 2dimensional drogue tracking on a finite element grid with linear finite elements. Skidaway Institute of Oceanography.

Bretherton, F. P., R. E. Davis, and C. B. Fandry, 1976: A technique for objective analysis and design of oceanographic experiments applied to MODE-73. Deep-Sea Res., 23, 559-582.

Butman, B., and R. C. Beardsley, 1987a: Physical oceanography introduction. Georges Bank, R. H. Backus, Ed., The MIT Press, 88-98.

$\longrightarrow$, and,$- 1987 \mathrm{~b}$ : Long-term observations on the southern flank of Georges Bank. Part I: A description of the seasonal cycles of currents, temperature, stratification and wind stress. J. Phys. Oceanogr., 17, 367-384.

,-- , B. Magnell, D. Frye, J. A. Versmersch, R. Schlitz, R. Limeburner, W. R. Wright, and M. A. Noble, 1982: Recent observations of the mean circulation on Georges Bank. J. Phys. Oceanogr., 12, 569-591.

Chapman, D. C., J. A. Barth, R. C. Beardsley, and R. G. Fairbanks, 1986: On the continuity of mean flow between the Scotian Shelf and the Middle Atlantic Bight. J. Phys. Oceanogr., 16, 758772.

Cheng, R. T., and V. Casulli, 1982: On Lagrangian residual currents with applications in South San Francisco Bay, California. Wat. Resour. Res., 18, 1652-1662.

- S. Feng, and P. Xi, 1986: On Lagrangian residual ellipse. Lecture Notes on Coastal and Estuarine Studies-Physics of Shallow Estuaries and Bays, J. van de Kreefe, Ed., Springer-Verlag, 102113.

Davies, A. M., and G. K. Furnes, 1980: Observed and computed $\mathbf{M}_{2}$ tidal currents in the North Sea. J. Phys. Oceanogr., 10, 237257.

Drinkwater, K. F., M. J. Graça, and J. W. Loder, 1992: Lagrangian current measurements from the Georges Bank Frontal Study, 1988-89. Part I: Drift buoy trajectories. Can. Data Rep. Hydrogr. Ocean Sci. No. 116: iv + 105 pp.

Flagg, C. N., B. A. Magnell, D. Frye, J. J. Cura, S. E. McDowell, and R. I. Scarlet, 1982: Interpretation of the physical oceanography of Georges Bank. EG\&G Environmental Consultants, Waltham, Mass. Final Report prepared for U.S. Dept. of Interior, Bureau of Land Management, $901 \mathrm{pp}$.

Greenberg, D. A., 1983: Modelling the mean barotropic circulation in the Bay of Fundy and Gulf of Maine. J. Phys. Oceanogr., 13, 886-904.

lles, T. D., and M. M. Sinclair, 1982: Atlantic herring: stock discreteness and abundance. Science, 215, 627-633.

Isaji, T., and M. L. Spaulding, 1984: A model of the tidally-induced residual circulation in the Gulf of Maine and Georges Bank. $J$. Phys. Oceanogr., 14, 1119-1126.

Jordan, G. F., 1962: Large submarine sand waves. Science, 136, 839848.

Loder, J. W., 1980: Topographic rectification of tidal currents on the sides of Georges Bank. J. Phys. Oceanogr., 10, 1399-1416.
D. G. Wright, C. Garrett, and B.-A. Juszko, 1982: Horizontal exchange on central Georges Bank. Can. J. Fish. Aquat. Sci., 39, $1130-1137$.

, C. K. Ross, and P. C. Smith, 1988: A space- and time-scale characterization of circulation and mixing over submarine banks, with application to the northwestern Atlantic continental shelf. Can. J. Fish. Aquat. Sci., 45, 1860-1885.

Longuet-Higgins, M. S., 1969: On the transport of mass by timevarying ocean currents. Deep-Sea Res., 16, 431-447.

Lynch, D. R., and C. E. Naimie, 1993: The $\mathrm{M}_{2}$ tide and its residual on the outer banks of the Gulf of Maine. J. Phys. Oceanogr., 23, 2222-2253.

- , F. E. Werner, D. A. Greenberg, and J. W. Loder, 1992: Diagnostic model for baroclinic, wind-driven and tidal circulation in shallow seas. Contin. Shelf Res., 12, 37-64.

Noble, M., B. Butman, and E. Williams, 1983: On the longshore structure of subtidal currents on the eastern United States continental shelf. $J$. Phys. Oceanogr., 13, 2125-2147.

Oey, L. Y., G. L. Mellor, and R. I. Hires, 1985: Tidal modelling of the Hudson Raritan Estuary. Estuar. Coast. Mar. Sci., 6, 353363.

Ottino, J. M., 1989: The Kinematics of Mixing: Stretching, Chaos and Transport. Cambridge University Press, $364 \mathrm{pp}$.

- C. W. Leong, H. Rising, and P. D. Swanson, 1988: Morphological structures produced by mixing in chaotic flows. Nature, 333, 419-425.

Page, F. H., 1990: The transport of haddock (Melanogrammus aeglefinus) eggs in the northwest Atlantic. Ph.D. thesis, Dalhousie University, $232 \mathrm{pp}$.

- and P. C. Smith, 1989: Particle drift in the surface layer off southwest Nova Scotia: Description and evaluation of a model. Can. J. Fish. Aquat. Sci., 46(Suppl. 1), 21-43.

Pasmanter, R. A., 1988: Anomalous diffusion and anomalous stretching in vortical flows. Fluid Dyn. Res., 3, 320-326.

Pierrehumbert, R. T., 1991: Chaotic mixing of tracer and vorticity by modulated travelling Rossby waves. Geophys. Astrophys. Fluid Dyn., 58, 285-319.

Perry, A. E., and M. S. Chong, 1987: A description of eddying motions and flow patterns using critical-point concepts. Ann. Rev. Fluid Mech., 19, 125-155.

Prandle, D., 1984: A modelling study of the mixing of Cs 137 in the seas of the European continental shelf. Phil. Trans. Roy. Soc. (A), 310, 407-436.

Ridderinkhof, H., 1989: Tidal and residual flows in the western Dutch Wadden Sea, III: Vorticity balances. Neth. J. Sea Res., 22, 926.

_ and J. T. F. Zimmerman, 1990: Mixing processes in a numerical model of the western Dutch Wadden Sea. Residual Currents and Long Term Transport, Coastal and Estuarine Studies, Vol. 38, R. T. Cheng, Ed., Springer Verlag, 194-209.

- , and -1992 : Chaotic stirring in a tidal system. Science, 258, 1107-1111.

-1, and M. E. Philippart, 1990: Tidal exchange between the North Sea and the Dutch Wadden Sea and mixing time scales of the tidal basins. Neth. J. Sea Res., 25, 331-350.

Ryrie, S. C., 1992: Mixing by chaotic advection in a class of spatially periodic flows. J. Fluid Mech., 236, 1-26.

Saunders, P. M., 1977: Wind stress on the ocean over the eastern continental shelf of North America. J. Phys. Oceanogr., 7, 555566.

Smith, P. C., 1983: The mean and seasonal circulation off southwestern Nova Scotia. J. Phys. Oceanogr., 13, 1034-1054.

, 1989: Circulation and dispersion on Browns Bank. Can. J Fish. Aquat. Sci., 46, 539-559.

Spaulding, M. G., S. B. Saila, E. Lorda, H. Walker, E. Anderson, and J. C. Craig, 1983: Oil-spill fishery impact assessment model: application to selected Georges Bank fish species. Estuar., Coast. Shelf Sci., 16, 51 1-541.

Tabor, M., 1989: Chaos and Integrability in Nonlinear Dynamics: An Introduction. John Wiley \& Sons, $364 \mathrm{pp}$. 
Tee, K.-T., P. C. Smith, and D. Lefaivre, 1987: Modelling and observations of the residual current off southwest Nova Scotia. Proceedings of the Eighteenth International Liege Colloquim on Ocean Hydrodynamics, J. C. J. Nihoul and B. M. Jamart, Eds., Elsevier Oceanogr. Ser., 45, 455-470.

$\ldots,-$, and -1 , 1993: Topographic upwelling off southwest Nova Scotia. J. Phys. Oceanogr., 23, 1703-1726.

Tremblay, M. J., J. W. Loder, F. E. Werner, C. E. Naimie, F. H. Page, and M. M. Sinclair, 1994: Drift of sea scallop larvae on Georges Bank: A model study of the roles of mean advection, larval behavior and larval origin. Topical Studies in Oceanography, in press.

Weiss, J. B., and E. Knobloch, 1989: Mass transport and mixing by modulated travelling waves. Phys. Rev. A, 40, 25792589 .
Werner, F. E., F. H. Page, D. R. Lynch, J. W. Loder, R. G. Lough, R. I. Perry, D. A. Greenberg, and M. M. Sinclair, 1993: Influences of mean advection and simple behaviour on the distributions of cod and haddock early life stages on Georges Bank. Fisheries Oceanography, 2, 43-64.

Wright, D. G., D. A. Greenberg, J. W. Loder, and P. C. Smith, 1986: The steady-state barotropic response of the Gulf of Maine to surface wind stress. J. Phys. Oceanogr., 16, 947-966.

Zimmerman, J. T. F., 1979: On the Euler-Lagrange transformation and the Stokes drift in the presence of oscillatory and residual currents. Deep-Sea Res., 26, 505-520.

- 1981: Dynamics, diffusion and geomorphological significance of tidal residual eddies. Nature, 290, 549-555.

- 1 1986: The tidal whirlpool: A review of horizontal dispersion by tidal and residual currents. Neth. J. Sea Res., 20, 133-154. 